\title{
Reflexões sobre a amamentação no Brasil: de como passamos a 10 meses de duração
}

\author{
A review of breastfeeding in Brazil and \\ how the country has reached ten months' \\ breastfeeding duration
}

Marina Ferreira Rea 1

1 Instituto de Saúde, Coordenação dos Institutos de Pesquisa, Secretaria de Estado da Saúde de São Paulo. Rua Santo Antônio 590, São Paulo, SP 01314-000, Brasil. marifrea@isaude.sp.gov.br
Abstract In 1975, one out of two Brazilian women only breastfed until the second or third month; in a survey from 1999, one out of two breastfed for 10 months. This increase over the course of 25 years can be viewed as a success, but it also shows that many activities could be better organized, coordinated, and corrected when errors occur. Various rel evant deci si ons have been made by international health agencies during this period, in addition to studies on breastfeeding that have reoriented practice. We propose to review the history of the Brazilian national program to promote breastfeeding, focusing on an analysis of the influence of international policies and analyzing them in four periods: 1975-1981 (when little was done), 1981-1986 (media campaigns), 1986- 1996 (breastfeeding-friendly policies), and 1996-2002 (planning and human resources training activiti es backed by policies to protect breastfeeding). The challengefor the future is to continue to promote exclusive breastfeeding until the sixth month, taking specific population groups into account.

Key words Breastfeeding; Governments Programs; Infant Nutrition

Resumo Se em 1975 uma em cada duas mulheres amamentava apenas até o segundo ou terceiro mês no Brasil, no úl timo inquérito de 1999, uma em cada duas mulheres amamenta até cerca de dez meses. Esse aumento em 25 anos pode tanto ser pensado como um sucesso, como pode ser visto como al go que poderia estar muito melhor se todas as atividades que se realizaram no país tivessem sido mantidas, avaliadas, corrigi das, bem coordenadas, melhoradas. Diversas foram as decisões de organismos internacionais de saúde no período, assi m como estudos sobre aleitamento que reorientaram ações. Propomo-nos a tentar rever a trajetória do programa nacional, privilegiando a anál ise da influência das políticas internacionais e analisando-o em quatro períodos: de 1975 a 1981 (quando pouco era feito), de 1981 a 1986 (as campanhas na mídia), de 1986 a 1996 (políticas em prol da amamentação) e de 1996 a 2002 (planejamento e ações de capacitação de recursos humanos com o respaldo das políticas de proteção). O desafio que se coloca para o futuro é a necessi dade de continuar a promover a amamentação exclusi va até o sexto mês, levando em conta grupos particulares da população.

Palavras-chave Aleitamento Materno; Programas Governamentais; Nutrição Infantil 


\section{Introdução}

Cientes de criteriosa revisão da literatura científica (Kramer \& Kakuma, 2002), os ministros de saúde aprovaram Resolução na 54a Assembléia Mundial de Saúde, da Organização Mundial da Saúde (OMS), recomendando que todas as crianças devem receber exclusivamente leite materno até cerca de seis meses de vida e que a amamentação deve ser mantida por pelo menos dois anos; e concluem que são três os grandes desafios a ser enfrentados pelos programas pró-amamentação neste século: (1) como manter a amamentação exclusiva desde o nascimento até o sexto mês, (2) como trabalhar a introdução do al imento complementar adequado sem interromper a amamentação a partir do sexto mês e (3) como promover a melhor alimentação infantil para grupos especiais da população (mães HIV positivas, catástrofes, etc.) sem causar distúrbios na prática de amamentar da população em geral.

Em 1984, foi publicada pela primeira vez uma meta-anál ise mostrando que amamentar exclusivamente até cerca de 4-6 meses protege a criança contra a morte por doenças infecciosas (Feachem \& Koblinsky, 1984). Victora et al. (1987), em estudo caso-controle, demonstraram que quanto mais leite materno exclusivo uma criança recebe, menor o risco de morrer por diarréia e outras infecções. Os conhecimentos das últimas duas décadas, evidenciam que vários são os agravos significativamente piores quando a amamentação não acontece, entre os quais: enterocolite necrotizante (Lucas \& Cole, 1990), diabetes (Karjalainen et al., 1992), alergias (Saarinen \& Kajosaari, 1995), pneumonia (César et al., 1999). M ostrou-se também, que o uso do leite materno para recém nascidos prematuros e de baixo peso leva a maiores índices de inteligência (Lucas et al., 1992) e acuidade visual (Birch et al., 1993). Por muitos anos desconheceu-se o valor nutricional e imunológico do leite materno e o valor do ato de amamentar e suas conseqüências fisiológicas, emocionais e de menor morbidade para o bebê e para a mãe (menos câncer de ovário - Gwinn et al., 1990 - e de mama pré-menopausa - Michels et al., 1996). Assim, atividades ou programas pró-amamentação eram desenhados sem muitos critérios. Os fatores determinantes do desmame mais as atividades pró-aleitamento materno mal executadas continuavam a levar ao uso do leite artificial e da mamadeira.

Durante a década de 80, diversos trabalhos mostraram que as atividades de amamentação, se bem estruturadas e principalmente, se multisetoriais e bem coordenadas, levavam ao au- mento da prática de amamentar. O Programa Nacional de Incentivo ao Al ei tamento Materno no Brasil (PNIAM) foi exemplar nesse sentido (Rea, 1989), mas atividades bem coordenadas também são descritas em outros países (Jelliffe \&Jelliffe, 1988).

Ações setoriais pró-amamentação têm de ser respaldadas por políticas gerais, como ficou claro na década de 70 na Nova Guiné (Biddulph, 1981). Neste país, em um momento em que se deu conta dos baixos índices de al eitamento materno, campanha pró-amamentação foi iniciada nas escolas de educação infantil, pelo rádio e imprensa, com a colaboração do comércio. Estes foram instados a restringir a venda de mamadeiras. Mas, percebeu-se que apenas se aprovassem uma lei que respaldasse as ações em andamento, estas poderiam ter efeito. Assim, fez-se uma legislação proibindo propaganda comercial de substitutos do leite materno e regulamentando sua venda. Mamadeiras passaram a ser vendidas apenas com prescrição de profissional de saúde. Após algum tempo observou-se que os índices de amamentação haviam aumentado.

Raros, entretanto, são os estudos de cidades ou países que mostrem avaliação de impacto de programas ou ações pró-amamentação. Refletindo sobre esse período, remeto o leitor à Figura 1, onde se procura listar as atividades ou "marcos" - internacionais e nacionais - que mais se destacaram nessa história, colocados próximo ao ano que essa atividade se destacou ou se iniciou, e a duração da amamentação (mediana em meses) naquele ano; essa duração é baseada em parte em dados de inquéritos nacionais (quando existem) e às vezes apenas de áreas urbanas representativas. Os dados dos inquéritos inicial e final estão mostrando que em 1975, uma em cada duas muIheres amamentava apenas até o segundo, terceiro mês, enquanto que em 1999, uma em cada duas mulheres leva a amamentação até cerca de dez meses. Esse aumento em 25 anos pode ser pensado como um sucesso? Ou poderia estar muito melhor se todas as atividades que se realizaram tivessem sido mantidas, avaliadas, corrigidas, bem coordenadas, melhoradas?

Este artigo tem como propósito rever a trajetória do programa, privilegiando a análise da influência das políticas internacionais sobre al eitamento materno, e analisando o processo, dividindo-o em quatro períodos (divisão um tanto arbitrária, em função de momentos com informações e dados nacionais e/ ou internacionais, nem sempre precisos): primeiro período (de 1975 a 1981), segundo (de 1981 a 1986), terceiro (de 1986 a 1996) e quarto (de 1996 a 2002). 


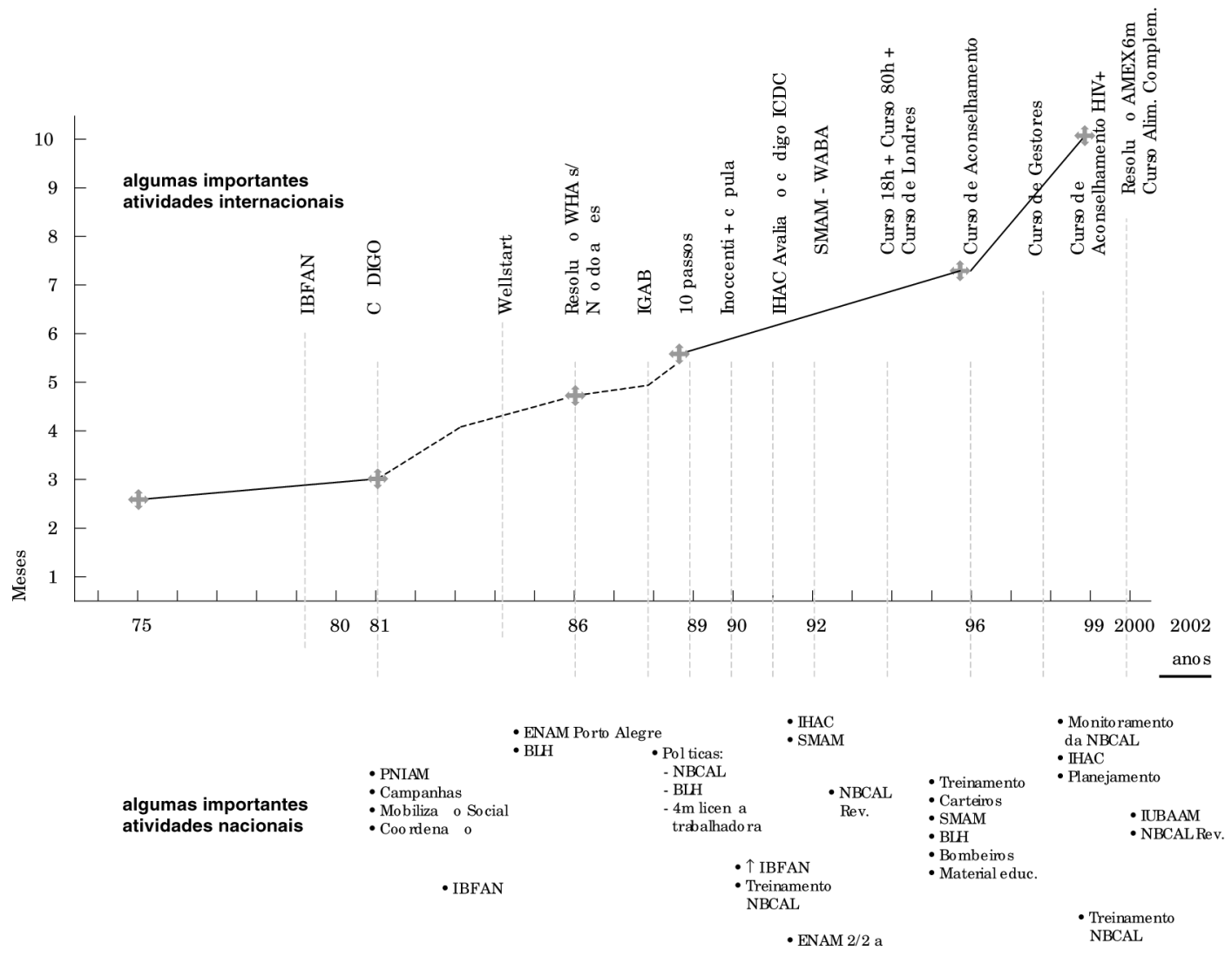

1o período - a década de 70 e o início dos anos 80

Não existem estudos nacionais com população sadia que documente os índices de amamentação em décadas anteriores aos anos 70, mas, por estudos isolados, pode-se estimar que a prática de amamentar registra seus pontos mais baixos nessa década, confirmados pelo inquérito domiciliar nacional que mostrou que era de 2,5 meses a mediana de amamentação (Venancio \& Monteiro, 1998).

A avaliação da situação em 1981, realizada nas áreas metropolitanas de São Paulo e Recife, revelou 2,8 e 2,4 meses, respectivamente, de duração mediana de amamentação (Berquó et al., 1984), permitindo-nos estimar que entre 1975 e aquele momento, ou seja, em cerca de seis anos, quase nada havia mudado. O que se pode dizer que constituía o panorama de atividades nesse período? O não incentivo ao aleitamento materno pelos pediatras, cujas esco- las eram permeadas pelas companhias de fórmulas infantis junto a professores e alunos, os quais orientavam a entrada de outros alimentos precocemente na dieta; propaganda não ética de substitutos do leite materno e grande venda desses produtos; distribuição gratuita de leite pelo governo, através dos chamados Programas de Suplementação Alimentar, onde a criança podia receber leite em pó desde o início da vida; e algumas ações de incentivo a amamentação em instituições isoladas, impulsionadas por profissionais pioneiros.

À mesma época, a preocupação com o desmame e com o papel da propaganda dos substitutos do leite materno levou o Secretário de Saúde de Pernambuco (Prof. Fernando Figueira) a proibir mamadeiras e leite gratuito nas unidades de saúde e maternidades desse estado.

É de 1978 o primeiro estudo (Goldemberg, 1988), que documenta no Brasil as práticas indevidas de marketing de substitutos do leite materno: são descritas formas de propaganda 
em revistas leigas desde 1916, e em revistas científicas como Pediatria Prática, Jornal de Pediatria, etc.

Nesse período, ocorre a Reunião Conjunta OMS/ UNICEF sobre Alimentação Infantil e da Criança Pequena (1979), organizada pela OMS, em Genebra. Entre outras, uma decisão deste evento foi que se deveria elaborar um código de conduta ética quanto à propaganda de produtos que interferiam na amamentação. O Brasil esteve lá representado pela presidência do Instituto Nacional de Alimentação e Nutrição (INAN), que colaborou na elaboração do Código Internacional de Comercialização de Substitutos do Leite Materno, fato importante, a nosso ver, para a decisão de um programa próamamentação neste país.

Em 1980, o INAN busca a ajuda da Organização Pan-Americana da Saúde (OPAS) e do Fundo das Nações U nidas para a I nfância (UNICEF), para elaborar um audiovisual sobre amamentação com a finalidade de sensibilizar políticos, autoridades de saúde, meios de comunicação de massa, líderes comunitários e de igreja, etc. Este audiovisual apoiava-se em pediatras famosos e apelava para a necessidade de acumular divisas no país em um momento de crise, dando relevância aos aspectos do valor econômico do leite materno, comparandoo aos gastos com leites artificiais. Após percorrer o país com esse material, técnicos do UNICEF e do INAN apresentaram-no aos ministros da saúde e previdência social, sendo decidido o lançamento do PNIAM.

Defendemos a tese de que as políticas próamamentação - tanto nacionais como internacionais - mostram-se fundamentais como respaldo às atividades programáticas locais (Rea, 1989). Segundo nossa análise, a decisão política tomada em 1981, por autoridades brasileiras de lançar um programa pode ser vista como resultado de: uma situação internacional favorável, uma análise adequada da situação e dos determinantes do desmame precoce e a necessi dade da volta à amamentação no nosso meio.

2o período - de 1981 a 1986

Os aspectos mais importantes do programa brasileiro pró-amamentação de 1981 foram: (1) ter uma coordenação nacional, (2) utilizar a mobilização social de todos os possíveis atores no tema e (3) contar com campanhas bem elaboradas na mídia. Com isso, o que se documenta em 1986, cinco anos após a primeira avaliação, é que a duração mediana da amamentação aumentou na Grande São Paulo, indo de 2,9 para 4,2 meses, e na Grande Recife, de 2,2 para 3,5 meses; nessa área, o al eitamento predominante, que era de 15 dias apenas, passou a 32 dias de duração mediana, com populações e instrumentos de coleta e análise comparáveis (Rea, 1990).

À mobilização social iniciada com o audiovisual acima mencionado, segue-se a primeira campanha na mídia, coberta por quase cem canais de televisão (alcance de 15,5 milhões de famílias) e seiscentas estações de rádio (vinte milhões de famílias), além de quatro propagandas na imprensa escrita visando a atingir líderes formadores de opinião. Por outro lado, folhetos de loteria esportiva, contas de água, telefone e energia, e extratos bancários veicuIaram o tema da campanha "Dêo Sei o ao Seu Filho Pelo Menos Durante os Seis Primeiros Me ses", por 45 dias, totalizando cerca de dez miIhões de contatos desse tipo. Os 17 textos musicados para rádio foram gravados em pequenos discos e distribuídos para 9 mil locutores difícil de se calcular o alcance e continuidade do uso deste meio. A estratégia de criar em cada estado uma coordenação estadual de entidades envolvidas no programa foi alcançada ao final de 1981, e muitos organismos tiveram papel destacado nessa atividade como a Igreja Católica (com a Conferência Nacional dos Bispos do Brasil - CNBB), o Movimento de Alfabetização (MOBRAL) e a Legião Brasileira de Assistência (LBA), com centenas de grupos de mães, além de associações de classe como a Federação Brasileira de Ginecologia e Obstetrícia e a Sociedade Brasileira de Pediatria (com reuniões científicas, publicações e mais de 70 mil impressos para mães).

Esse tipo de mobilização torna difícil quantificar quantos eventos, seminários, cursos ou treinamentos foram oferecidos. Isso ocorreu de forma heterogênea e sem material didático unificado, com poucos textos em Português disponíveis para treinamento ou atualização em aleitamento. O U NICEF apoiou a realização de duas pesquisas: uma quantitativa, dando ao programa dados básicos de como estava a situação do al eitamento no Brasil, e uma qualitativa, que permitiu conhecer de forma mais aprofundada que mensagens contra o desmame precoce poderiam ser mais apropriadas. À época, lança-se a Portaria sobre Alojamento Conjunto, determinando que as maternidades com leitos pagos pela previdência social deveriam oferecer leitos no mesmo quarto às parturientes e seus recém-nascidos. Em geral, as maternidades adotavam até aquele período regras rígidas de separação mãe e filho no pósparto, uso de soro glicosado como rotina de alimento pré-lácteo, horários fixos de mama- 
das, complementação com mamadeira e outras medidas inadequadas de manejo clínico da lactação (Berquó et al., 1984).

Outras políticas de proteção à amamentação quase não foram feitas nessa época, embora registremos a revisão dos benefícios da mãe trabalhadora e lactante, e a tentativa de transformação do código internacional em norma brasileira. O código havia sido aprovado em Assembléia na OMS em maio de 1981; a proposta de haver uma norma nacional nele baseada foi arquivada em 1983 pelo INAN, após parecer da consultoria jurídica do Ministério da Saúde (MS).

Desde antes do lançamento do código e mais sistematicamente após sua entrada em vigor, as companhias de fórmulas infantis estavam sob pressão internacional dos grupos IBFAN (International Baby Food Action Network), para interromper suas formas de promoção comercial não éticas. O grupo IBFAN que se havia iniciado no país em 1983, era pouco expressivo tendo dificuldades de monitorar as práticas de marketing. Mas como internacionalmente essa rede realizava um boicote à Nestlé, e esta era a companhia que praticamente monopolizava as vendas de leites infantis no país, fomos beneficiados indiretamente por esse boicote, já que essa companhia mudou seus rótulos e outras formas de propaganda também no Brasil (Rea \& Toma, 1997).

A segunda campanha, em 1982-1983, pelos meios de comunicação de massa, foi mais bem trabalhada que a primeira. Valendo-se da experiência da anterior e das pesquisas quantitativa e qualitativa, foi feito inicialmente um planejamento estratégi co de campanha. Sabendo-se que cerca de $90 \%$ de mulheres no Brasil iniciavam a amamentação, a mensagem não poderia ser como em países onde menos de $70 \%$ de mães iniciam a amamentação, como nos Estados Unidos, por exemplo. Era preciso trabalhar sobre a sustentação da amamentação. Não dizer “Amamente!”, mas sim: “Amamentação: continue; toda a mulher pode". Para atacar as causas de desmame precoce, centrou-se na pesquisa qualitativa, que informava que: muitas mulheres acreditam que seu leite é "fraco", ficam ansiosas e por isso introduzem mamadeira; outras acham que seus seios podem "cair" devido à amamentação; outras pensam que voltar ao trabalho impede a mãe de continuar dando o peito e outras tantas acreditam no pediatra, cuja formação trazia mais informações sobre como prescrever uma fórmula infantil do que como orientar sobre o manejo clínico da lactação. Foram contratados artistas e personalidades famosas, e cada um deles passava men- sagens relacionadas aos temas acima descritos, em cinco comerciais pela TV.

A campanha foi veiculada nos intervalos comerciais pelas empresas de televisão Globo, Bandeirantes e TVS. Houve merchandising na novela Louco Amor e na Revista Manchete. A audiência estimada, alcançada considerando a população com televisão e o tempo de exposição, foi de 500 milhões de espectadores em São Paulo e 169 milhões em Recife (CBBA, 1980), sem contar nas demais cidades. Vale notar que, nesse mesmo período, era freqüente a presença de comerciais de "alimentos infantis Nestlé", de mamadeiras e bicos diversos, além de comerciais esporádicos de leite Ninho e leite tipo B usados no preparo de fórmula infantil caseira.

Como parte do planejamento da campanha, foi distribuído um kit sobre amamentação a jornalistas. Com isso, entre 13 de fevereiro de 1983 e 27 de março de 1983, 78 artigos sobre o tema, em diversas revistas para leigos foram encontrados em 25 cidades brasileiras (Jelliffe $\&$ Jelliffe, 1983).

Nos anos de 1984/1985/ 1986, as atividades pró-amamentação continuam a ser registradas nos estados, mas passa a haver um enfraquecimento da coordenação do programa, na medida em que o MS, em dezembro de 1983, publica uma portaria onde ações de incentivo ao aleitamento deveriam fazer parte das Ações Integradas de Saúde. Nessa época, o UNICEF também redireciona suas prioridades para o GOBI (Growth, Oral rehidration, Breastfeeding, Immunization) conjunto de ações básicas de saúde infantil.

Em 1985, o INAN realiza em Porto Alegre, um Evento Nacional de Aleitamento Materno (ENAM) e o Instituto Fernandes Figueira (IFF), da Fundação Oswaldo Cruz, Rio de Janeiro, inicia a implantação de Bancos de Leite Humano (BLH), uma atividade antes esporádica em um ou outro hospital do país.

Em nível internacional, importante marco referencial na história da amamentação ocorre em 1986, na Assembléia Mundial de Saúde, quando se vota a resolução que clarifica o artigo 6 do código sobre doações de substitutos de leite materno, como sendo desnecessárias a maternidades, pois sendo poucos os bebês que são exceção ao uso do leite humano, sua alimentação deve ser adquirida pelos canais normais de compras de medicamentos. Define também que os chamados "leites de seguimento" são desnecessários. 
3o período - de 1987 a 1996

No final da década de 80, apropriando-se da informação de que o aleitamento materno exclusivo no início da vida é fundamental, autoridades da OMS, do UNICEF, de organismos bilaterais e técnicos passam a se reunir no sentido de elaborar uma estratégia que levasse em conta os diversos determinantes que interferiam nessa prática, criando-se o IGAB (International Group on Action on Breastfeeding). Este aprofunda como trabal har aqueles determinantes: serviços de saúde e hospitais; grupos de mães e comunidade; treinamento (destacando-se os cursos de especialização em lactação humana do Wellstart International, de San Diego, Estados Unidos); comunicação, educação, código e mulher trabalhadora. Esse processo se encerra com a Declaração de Inoccenti (1990).

Em 1989, a OMS e o UNICEF Iançam um documento que se pode reputar como fundamental hoje em qualquer atividade programática: a Declaração Conjunta sobre o Papel dos Servi ços de Saúde e M aterni dades (OM S/UNICEF, 1989), onde se mencionam dez ações relacionadas a incentivar 0 al eitamento materno, com o resumo do que as maternidades deveriam fazer - os chamados dez passos para o sucesso do aleitamento materno. Em um momento onde não havia textos internacionais disponíveis de capacitação de pessoal em aleitamento e orientação sobre rotinas de pré-natal e parto, essa declaração passa a ocupar importante lacuna.

Quanto à Declaração de Inoccenti, diferentemente de qualquer outro documento internacional produzido antes pelas autoridades de saúde, ela foi o resultado de um longo e participativo processo de análise, e traz metas definidas e objetivos claros a serem alcançados pelos países na promoção da amamentação: fortalecer a mul her na sua decisão de amamentar exclusivamente até os 4 ou 6 meses de vida e continuar amamentando, com alimentos complementares, até o segundo ano de vida ou mais. E resume quatro ações fundamentais para que isso ocorra: (1) ter uma coordenação e um comitê pró-amamentação, (2) assegurar que as maternidades cumpram os dez passos para o sucesso do aleitamento materno, (3) implementar todo o código e resoluções subseqüentes relevantes da Assembléia Mundial de Saúde e (4) buscar formas imaginativas de proteger a mulher trabalhadora lactante, respeitando seus benefícios.

No Brasil, o final dos anos 80 representou um período de retomada da coordenação do programa e em 1987 é dado impulso principalmente às equipes de trabal ho do código, dos bancos de leite, de mulher e trabalho, e de educação e comunidade. Os resultados consolidam em 1988, pelo menos quatro políticas próamamentação no país: aprovamos nosso código, denominado Norma Brasilei ra de Comercialização de Alimentos para Lactentes, após meses de negociações com a indústria de alimentos; estabelecemos normas sobre funcionamento dos BLH ena nova Constituição Brasileira conseguimos incluir pelo menos dois benefícios em prol da amamentação: o direito da trabal hadora a quatro meses de licença maternidade e o direito ao pai a cinco dias de licença paternidade.

Em maio de 1988, o MS regulamenta os BLH com normas sanitárias e de capacitação técnica, tendo o IFF (primeiro BLH do país em 1943) como referência nacional e estabelecendo que os bancos não deveriam ser apenas locais de coleta, processamento e estocagem de leite humano, mas sim centros nucleadores de atividades pró-amamentação.

A Cúpula Mundial da Infância (1990), com a participação do Brasil, estabeleceu metas para a década, algumas sobre aleitamento: garantir a duração da amamentação conforme recomendado em Inoccenti, garantir que $50 \%$ dos hospitais que atendam mil partos ou mais sejam credenciados como hospitais "Amigos da Criança" e terminar com a distribuição de sucedâneos de leite materno nos serviços de saúde. Assim, tanto a Declaração de Inoccenti como a cúpula representaram marcos importantes que influenciaram a reordenação do programa pró-amamentação brasileiro.

Em 1991 foi lançada a Iniciativa Hospital Amigo da Criança (IHAC), com dois objetivos: mudar as rotinas hospitalares segundo o cumprimento dos "Dez Passos Para o Sucesso da Amamentação" e não aceitar doações de substitutos do leite materno. Esta iniciativa cria pela primeira vez um referencial de avaliação internacional único para os hospitais. No Brasil, a IHAC começou em 1992. Até 1996 o crescimento de hospitais foi acelerado, sendo esse o ano com maior número de hospitais credenciados. Se a velocidade de aprovação de novas maternidades continuasse como vinha acontecendo, chegaríamos a 2000 com cerca de quatrocentos Hospitais Amigos da Criança; nesse ano, entretanto, o MS decide agregar prérequisitos para que os hospitais se credenciem, além dos dez passos, entre os quais uma taxa mais baixa de cesáreas; desacelera-se a IHAC desde então, e em 2000 não havíamos atingido nem a metade do que foi pretendido. 
O UNICEF, profissionais independentes e diversas organizações não governamentais (entre as quais: IBFAN, La Leche League, ILCA - International Lactation Consultant Association -, Wellstart, etc.) preocupados com a possibilidade da não implementação de políticas com metas tão importantes que haviam sido decididas no início da década de 90 , decidem criar em fevereiro de 1992 a Aliança Mundial de Ações Pró-Amamentação (WABA). Essa coalizão mostrou-se fundamental para instigar anualmente a participação de grupos e pessoas na Semana Mundial de Amamentação, quando temas diferentes são tratados, como a questão da IHAC, do trabalho da mulher, da educação, etc. No nosso país a Semana Mundial deAmamentação tem tido atuação destacada, está presente hoje em inúmeros municípios ejá se avaliou que cumpre esse papel de mobilizador social para o qual ela foi originalmente criada (Siqueira \& Toma, 2001).

4o período - de 1996 a 2002

Neste último período em análise, nota-se um incremento na duração da amamentação de cerca de três meses em três anos, ou seja, a duração mediana vai de sete meses (BEMFAM/ DHS/IBGE/M S/ UNICEF, 1997) a aproximadamente dez meses em 1999 (lembramos que este é um dado referente às capitais do país, exceto Rio de Janeiro, baseado na pesquisa realizada pelo MS em 1999. Sabendo-se que a amamentação costuma ser mais prolongada em cidades pequenas e em zonas rurais, admite-se que este dado esteja subestimado).

Internacionalmente OMS e UNICEF colocam à disposição quatro cursos de amamentação para públicos-alvo diferentes: um curso de 18 horas para equipes de hospitais que querem fazer parte da IHAC; um de oitenta horas para formar monitores; um de aconselhamento com quarenta horas (com oito horas de prática), para os que lidam diretamente com mães e bebês e um curso rápido de sensibilização para chefias. Estes materiais são traduzidos para o Português por iniciativa da rede IBFAN e passam a ser utilizados pelo MS.

Capacitar pessoal passa a ser uma das atividades mais importantes do programa neste último período sob análise. A partir de uma coordenação em 1997, que planeja todas as ações com metas e recursos bem definidos, os cursos acima, exceto o de oitenta horas, passam a ser amplamente utilizados em todas as regiões do país, e junta-se a eles os cursos próprios para capacitar o pessoal de BLH e o curso sobre a Norma Brasileira de Comercialização de Ali- mentos para Lactentes (NBCAL), ministrados pelos monitores da IBFAN. Apenas neste período estima-se que foram capacitados mais profissionais do que em toda a história do programa.

Os fiscais sanitários, o pessoal ligado à defesa do consumidor e as procuradorias jurídicas passam a ser o grupo alvo da capacitação sobre a NBCAL, realizada pela rede IBFAN, por um acordo com o MS. Nesses treinamentos, agrega-se um componente prático de monitoramento da norma, o que dá ao MS pela primeira vez resultados nacionais sobre o cumprimento da legislação sobre alimentos infantis, bicos, chupetas e mamadeiras. A partir de 1999, com o apoio de um consultor da Procuradoria Jurídica do Distrito Federal, o MS toma medidas de diálogo e imposição de regras às companhias infratoras. Isso foi crítico para se notar a necessidade de rever pela segunda vez a NBCAL, o que é feito nos anos 2000-2001, publicando-se novas portarias mais abrangentes e melhor detalhadas.

Quanto à IHAC, o credenciamento de hospitais que havia diminuído em 1996, volta a se acelerar. Dos cerca de 250 “Hospitais Amigo da Criança" existentes no Brasil em 2002, a grande maioria está no Nordeste e é público ou filantrópico.

O crescimento da rede de $\mathrm{BLH}$, chegando perto de 150 bancos tem sido notável nos anos recentes, em particular com vigilância e capacitação de equipes por todas as regiões. A coleta de leite domiciliar é feita em parceria com o Corpo de Bombeiros (Projeto Bombei ro Amigo).

Outra atividade em destaque no último período é a parceria com os Correios e Telégrafos na Semana Mundial de Amamentação, que iniciou-se no Ceará, em seguida em nove estados nordestinos e desde 2001 está em quase todos os estados do país. Não há estudos avaliando o alcance e impacto de tais atividades.

\section{E o futuro?}

Os organismos internacionais decidiram rever as metas da Declaração de Inoccenti dez anos depois e repensar o que passou a ser chamado Estratégia Global sobre Alimentação Infantil e da Criança Pequena (GSIYCF), Iançada no ano de 2002 (aprovada como resolução da Assembléia Mundial de Saúde, na OMS, em 2002). As bases desta estratégia significam reafirmar aquela declaração, ou seja, a necessidade de incentivar a amamentação exclusiva por seis meses, e buscar formas ótimas de promover a alimentação complementar adequada sem in- 
terromper a amamentação até pelo menos o segundo ano de vida. E incluir a problemática de como trabal har essas duas recomendações entre os chamados grupos em circunstâncias especiais (mães HIV positivas e famílias em situações de emergência).

Trabalhando nessa linha, já estão disponíveis pela OMS e UNICEF, um curso de aconseIhamento para mães HIV positivas, materiais de referência do Programa Conjunto das Nações Unidas sobre HIV/ AIDS (UNAIDS), da OMS e do UNICEF sobre HIV e alimentação infantil, materiais sobre as opções de alimentação em situações de emergência e como aconselhar alimentação complementar.

No Brasil, a mensagem e a política em prol da amamentação exclusiva por seis meses já está em vigência há mais de dez anos, e dessa forma, pudemos atuar decisivamente pela sua aprovação na Assembléia Mundial de Saúde em 2001, pois mostramos que é possível incrementar o aleitamento exclusivo: estima-se um aumento de cerca de dez vezes na prevalência de aleitamento materno exclusivo de 0 a 4 meses, que era de cerca de $3.8 \%$ em 1986 e aumenta cerca de dez vezes em 1996 (BEMFAM/ DHS/IBGE/MS/UNICEF, 1997).

Levando-se em conta os acertos e erros do programa nos anos anteriores, e a necessidade de melhorar os índices de amamentação no país, a proposta atual do MS é continuar a centrar as atividades naquelas já delineadas anteriormente, redirecionar o trabalho intensificando a atenção humanizada ao recém-nascido com o método mãe canguru e o uso de leite humano e implantar a I niciativa Unidades Básicas Amigas da Amamentação (IUBAAM) nos ambulatórios que fazem atenção primária, para melhorar a sustentação do aleitamento materno. Entretanto, ao se rever as quatro estratégias da Declaração de Inoccenti vê-se que a menos executada no nosso país é a referente ao incentivo à amamentação de mães trabalhadoras; ações dirigidas a esse grupo populacional necessitam de estudos cuidadosos que demonstrem o que seria mais custo-efetivo.

Refletindo sobre todos os estudos publicados nesse período e as ações realizadas, destacamos como desafio a avaliação de todo o processo recente e o impacto das ações de aleitamento do país sobre a morbi-mortalidade e o crescimento infantil, o que acreditamos ser uma lacuna de pesquisa a ser preenchida, dando respostas especialmente àqueles que ainda questionam sobre o porquê dos grandes esforços desenvolvidos por diversas pessoas e instituições neste tema.

\section{Agradecimentos}

A Maria de Fátima Moura Araújo, responsável pela Coordenação do Aleitamento Materno da Área de Saúde da Criança, Secretaria de Políticas de Saúde, Ministério da Saúde. 


\section{Referências}

BEMFAM (Sociedade Civil Bem-Estar Familiar no Brasil)/DHS (Demographic and Health Survey)/ IBGE (Fundação Instituto Brasileiro de Geografia e Estatística)/MS (Ministério da Saúde)/UNICEF (Fundo das Nações Unidas para a Infância), 1997. Pesquisa Nacional sobre Demografia e Saúde. Rio de Janeiro: BEMFAM/DHS/IBGE/MS/UNICEF.

BERQUÓ, E.; CUKIER, R.; SPINDEL, C. R. \& REA, M. F., 1984. Caracterização e determinantes do aleitamento materno na Grande São Paulo e na Grande Recife. Cadernos CEBRAP, 2.

BIDDULPH, J., 1981. Promotion of breastfeeding in Papua New Guinea. In: Advances in Maternal and Child Health (D. B. Jelliffe \& E. F. P. Jelliffe, ed.), v. 1, pp. 169-174, New York: Oxford University Press.

BIRCH, E. E.; BIRCH, D. G.; HOFFMAN, D. R.; HALE, L.; EVERETT, M. \& UAUY, R., 1993. Breastfeeding and optimal visual development. Journal of Pediatric Ophtalmology and Strabismus, 30:33-38.

CBBA (Castelo Branco, Borges e Associados), 1980. Relatório de Pesqui sa sobre Al eitamento. São Paulo: CBBA/Fundo das Nações Unidas para a Infância. (mimeo.)

CÉSAR, J. A.; VICTORA, C. G.; BARROS, F. C.; SANTOS, I. S. \& FLORES, J. A., 1999. I mpact of breastfeeding on admission for pneumonia during postneonatal period in Brazil: Nested case-control study. BMJ, 318:1316-1320.

FEACHEM, R. G. \& KOBLINSKY, M. A., 1984. Interventions for the control of diarrhoea diseases among young children: Promotion of breastfeeding. Bulletin of the World Health Organization, 62:271291.

GOLDENBERG, P., 1988. Repensando a Desnutrição como Questão Social. Campinas: Editora Unicamp.

GWINN, M. L.; LEE, N. C.; RHODES, P. H.; LAYDE, P. M. \& RUBIN, G. L., 1990. Pregnancy, breast feeding, and oral contraceptives and the risk of epithelial ovarian cancer. Journal of Clinical Epidemiology, 43:559-568.

JELLIFFE, D. B. \& JELLIFFE, E. F. P. (ed.), 1988. Programmes to Promote Breastfeeding. New York: Oxford University Press.

JELLIFFE, E. F. P. \& JELLIFFE, D. B., 1983. The Brazilian National Breastfeeding Program. Report of a Visit. Brasília: Ministério da Saúde. (mimeo.)

KARJALAINEN, J.; MARTIN, J. M.; KNIP, M.; ILONEN, J.; ROBINSON, B. H.; SAVILAHTI, E.; AKERBLOM, H. K. \& DOSCH, H. M., 1992. A bovine albumin peptide as a possible trigger of insulin-dependent diabetes mellitus. New England Journal of Medicine, 327:302-307.
KRAMER, M. S. \& KAKUMA, R., 2002. Optimal duration of exclusive breastfeeding (Cochrane Review). In: The Cochrane Library, v. 4, CD003517. Oxford: U pdate Software.

LUCAS, A. \& COLE, T. J., 1990. Breast milk and neonatal necrotizing enterocolitis. Lancet, 336:15191523.

LUCAS, A.; MORLEY, R.; COLE, T. J.; LISTER, G. \& LEESON-PAYNE, C., 1992. Breast milk and subsequent intelligence quotient in children born preterm. Lancet, 339:261-264.

MICHELS, K. B.; WILLETT, W. C.; ROSNER, B. A.; MANSON, J. E.; HUNTER, D. J.; COLDITZ, G. A.; HANKINSON, S. E. \& SPEIZER, F. E., 1996. Prospective assessment of breastfeeding and breast cancer incidence among 89,887 women. Lancet, 347: 431-436.

OMS (Organização Mundial da Saúde)/UNICEF (Fundo das Nações Unidas para a Infância), 1989. Declaração Conjunta: O Papel Especial dos Serviços Materno-Infantis. Brasília: OMS/UNICEF.

REA, M. F. \& TOMA, T. S., 1997. Rótulos de alimentos infantis: Alguns aspectos das práticas de marketing no Brasil. Revista de Nutrição da PU CCAMP, 10: 127-135.

REA, M. F., 1989. As Políticas de Alimentação Infantil e a Prática deAmamentar: O Caso de São Paulo. Tese de Doutorado, São Paulo: Faculdade de Medicina, Universidade de São Paulo.

REA, M. F., 1990.The Brazilian National Breastfeeding Program: A success story. International Journal of Gynaecology and Obstetrics, 31(Sup. 1):79-82.

SAARINEN, U. M. \& KAJOSAARI, M., 1995. Breastfeeding as prophylaxis against atopic disease: Prospective follow-up study until 17 years old. Lancet, 346:1065-1069.

SIQUEIRA, S. R. \& TOMA, T. S., 2001. As Semanas Mundiais de Amamentação. In: Aleitamento Materno (J. D. Rego, org.), pp. 367-384, Rio de Janeiro: Editora Atheneu.

VENANCIO, S. I. \& MONTEIRO, C. A., 1998. A tendência da prática da amamentação no Brasil nas décadas de 70 e 80. Revista Brasileira de Epidemiologia, 1:40-49.

VICTORA, C. G.; SMITH, P. G.; VAUGHAN, J. P.; NOBRE, L. C.; LOMBARDI, C.; TEIXEIRA, A. M.; FUCHS, S. M.; MOREIRA, L. B.; GIGANTE, L. P. \& BARROS, F. C., 1987. Evidence for protection by breastfeeding against Infant deaths from infections diseases in Brazil. Lancet, 2:319-321.

Recebido em 4 de junho de 2002

Versão final reapresentada em 28 de outubro de 2002 Aprovado em 11 de dezembro de 2002 